\title{
LA RAZÓN Y EL DESEO: EL PROBLEMA DE LA EMANCIPACIÓN EN SCHILLER, HERDER Y NOVALIS
}

\author{
Alejandro Martín Navarro \\ bttps://orcid.org/0000-0002-0416-6927 \\ Universidad de Sevilla \\ bttps://doi.org/10.15304/ag.40.2.6699
}

\section{Resumen}

En el presente artículo se aborda el tratamiento dado por Schiller, Herder y Novalis al problema de la emancipación. Comenzaremos planteando la problemática específicamente moderna a la que se enfrentan estos autores, caracterizada por la metafísica mecanicista, la religiosidad reformada y la fragmentación sociopolítica; en segundo lugar, analizaremos la concepción kantiana de la razón práctica en su dimensión emancipatoria, esto es, como impugnación crítica del carácter condicionado de la realidad empírica; por último, esbozaremos las líneas fundamentales de una filosofía de la emancipación en la obra teórica de Schiller, Herder y Novalis.

Palabras clave: razón, emancipación, Schiller, Herder, Novalis.

\begin{abstract}
Purpose of this paper is to present how Schiller, Herder and Novalis address the question of emancipation. I will start setting out the specifically modern problems, which those thinkers confronted, characterized by the mechanistic metaphysics, the positive religion and the socio-political fragmentation; secondly, I will analyze the Kantian perspective on practical reason in its emancipating dimension, that is, as a critical negation of the conditioned nature of empirical world; finally, I will outline the main ideas of a philosophy of emancipation in the theoretical work of Schiller, Herder and Novalis.
\end{abstract}

Keywords: reason, emancipation, Schiller, Herder, Novalis.

Recibido: 29/03/2020. Aceptado: 30/06/2020. 


\section{Un molino que se muele a sí mismo}

Eine sich selbst mahlende Müble ${ }^{1}$ - tal es la famosa imagen con que Novalis describiera, en el último año del siglo XviıI, el edificio entero de la modernidad. La metáfora, que encontramos en su obra La Cristiandad o Europa, expresa la esencia mecanicista de la modernidad, esa que se adivina en la arquitectura conceptual de Spinoza tanto como en los sorprendentes autómatas de Jaquet-Droz. El molino que se muele a sí mismo también escenifica el ideal de un perpetuum mobile que reprodujera la aspiración moderna a una energía ilimitada, una máquina que no necesitara consumir más que la propia energía que ella misma produce y que supondría la consumación utópica del capitalismo: una producción potencialmente infinita. Por otro lado, frente al Dios aristotélico que mueve sin ser movido atrayendo todas las cosas hacia sí, el perpetuum mobile de la modernidad se nos manifiesta como un absoluto en movimiento, que contiene en sí todas las cosas y que no es más, de hecho, que el acto mismo de su producción y destrucción. Los ideales emancipadores que aparecen en las grandes obras de la modernidad, en los textos de Kant tanto como en los escritos de los reformadores religiosos, dejan traslucir la realidad efectiva de una época que, en su esfuerzo por ilustrar, ha terminado creando un mundo vacío de significación y de sentido. Lo mismo puede decirse respecto a la religión, como veremos: si el cristianismo específicamente moderno, encarnado en la Reforma protestante, se ve a sí mismo como impugnación de la sumisión arbitraria a la autoridad y al pasado, pronto va a revelarse como una nueva forma, más sutil, de postración ${ }^{2}$. De ahí que la propia reivindicación schilleriana de una belleza moral evidencie el hecho de que la libertad no se ve por ninguna parte. Schiller captó, en efecto, qué terriblemente opresivo es para los seres humanos el peso de un mundo sin belleza, esto es, el peso de un mundo dominado, también estéticamente, por el molino autófago de la ciencia, la política y la cultura moderna. Esta es la paradoja implícita en la modernidad como ideología: el ideal emancipador, aceptado como absoluto, lanza al individuo a formas nuevas y más sutiles de sumisión.

El hombre prehistórico tuvo que enfrentarse a una naturaleza interior y exterior que le resultaba desconocida y adversa: se le presentaba en forma de pulsiones ingobernables, fenómenos meteorológicos, enfermedad, frío y

${ }^{1}$ Novalis, Schriften: die Werke Friedrich von Hardenbergs (en adelante NS), StuttgartBerlin-Köln-Mainz, Kohlhammer Verlag, II, p. 741. Serán traducción propia los textos citados en ediciones en lengua extranjera.

2 Cf. NS, III, pp. 508-509. 
muerte, que a menudo comprendía como manifestaciones de fuerzas divinas. El hombre antiguo tuvo que enfrentarse con la tiranía de los sentidos, tanto en un plano gnoseológico (como expansión del conocimiento al mundo de lo matemático y de lo metafísico) como en un plano ético (en cuanto lucha contra la tiranía de las pasiones) y un plano espiritual (representado por la búsqueda de la santidad y el encuentro con lo divino). Kant -y los grandes teóricos de la libertad que vinieron tras él, desde Fichte a la Escuela de Frankfurt pasando por Schiller y Hegel— va a tener que enfrentarse a la prisión específicamente moderna: una prisión construida, al mismo tiempo, por la especialización social del Estado moderno (la disgregación de los conocimientos y estamentos descrita por Schiller) y por la emergente cosmovisión científica basada en una explicación mecanicista del mundo.

Hay que tener en cuenta que el procedimiento subyacente a la cosmovisión moderna es la matematización del mundo que comienza en el Renacimiento: el universo es concebido como un inmenso mecanismo gobernado por leyes inflexibles, leyes que pueden ser conocidas y expresadas en ecuaciones matemáticas. El resultado final de un pensamiento que afirma que toda la realidad está sujeta a leyes mecánicas es la idea de que el hombre también está sujeto a dichas leyes y que, por tanto, no es libre. Lo expresa con claridad geométrica Spinoza: "Los hombres se imaginan ser libres, porque son conscientes de sus voliciones y de sus apetitos, y ni soñando piensan en las causas que les disponen a apetecer y querer, porque las ignoran"3. Y en una de sus cartas lo explica con la famosa metáfora de la piedra arrojada al vacío: "Una piedra recibe de una causa externa, que la impulsa, cierta cantidad de movimiento con lo cual, después de haber cesado el impulso de la causa externa, continuará necesariamente moviéndose. (...) Conciba ahora, si lo desea, que la piedra, mientras prosigue su movimiento, piensa y sabe que ella se esfuerza, cuanto puede, por seguir moviéndose. Sin duda esa piedra, como tan sólo es consciente de su conato y no es de ningún modo indiferente, creerá que es totalmente libre y que la causa de perseverar en el movimiento no es sino que así lo quiere. Y ésta es la famosa libertad humana, que todos se jactan de tener, y que tan sólo consiste en que los hombres son conscientes de su apetito e ignorantes de las causas por las que son determinados" ${ }^{4}$. Así pues, el universo se revela como una inmensa jaula de hierro (tal es la metáfora que usará Max Weber para describir, en

\footnotetext{
${ }^{3}$ Spinoza, B., Ética demostrada según el modo geométrico, Madrid, Alianza, 1998, trad. de Vidal Peña, p. 97.

${ }^{4}$ Spinoza, B., Correspondencia, carta 58, Madrid, Alianza, 1988, pp. 336-337.
} 
otro orden de cosas, al Estado moderno) en la que el hombre está atrapado, prisionero de unas leyes naturales que determinan su conducta y su destino.

También el panorama espiritual resulta perversamente opresivo: si la Reforma es vista, en un primer momento, como la eclosión de la libertad en una religión dominada por la autoridad y la superstición (así la verá, todavía, Hegel), amplios círculos intelectuales alemanes van a detectar muy pronto las nuevas formas de sumisión a las que esa nueva religión conduce. Tal es el caso, desde luego, de Novalis, pero también de quienes de un modo u otro tuvieron contacto con los collegia pietatis o con alguna de las muchas heterodoxias que, entroncando con movimientos milenaristas y panteístas medievales, se extendían por Centroeuropa durante el siglo XviII. Y este terremoto teológico lo veremos perfectamente plasmado en la visión de la historia que se conforma en el seno del movimiento clásico-romántico ${ }^{5}$. Por ejemplo: entre los círculos pietistas alemanes, en los que se formaron Schiller, Novalis y Herder como tantos otros de su generación, se habían extendido las ideas de Joaquin di Fiore acerca de la historia entendida como el desarrollo del espíritu a lo largo de tres edades (la Edad del Padre, la Edad del Hijo, la Edad del Espíritu), siendo esta última aquella época de reconciliación definitiva que aún habría de llegar. Estas ideas — de evidente arraigo en los movimientos místicos y milenaristas medievales- serían recogidas y tematizadas por Lessing, pero influirían en toda la filosofía de la historia del xviı alemán. Pronto la mayoría de pensadores educados en el pietismo y bajo la autoridad intelectual de Lessing concebirán que los últimos años del siglo XviıI constituyen un momento de quiebra en la historia, un tránsito a una época definitiva presagiada por los grandes acontecimientos del presente: la emancipación política, la filosofía idealista y la eclosión cultural alemana, o en palabras de Schlegel: "La Revolución Francesa, La Doctrina de la Ciencia de Fichte y el Wilhelm Meister de Goethe son las más grandes tendencias de la época" ${ }^{6}$. La vinculación de este proyecto emancipador con el contenido no positivo de la religión cristiana lo percibe Novalis cuando sentencia: "Absoluta abstracción, aniquilación del presente, apoteosis del futuro, del mundo propiamente mejor, esta es la médula del mandato del cristianismo"7.

${ }^{5}$ Hacemos nuestra la expresión acuñada hace un siglo por Hermann A. Korff para designar lo que de común hay entre los movimientos clásico y romántico, especialmente en su recepción del kantismo, idea recogida después por Benz, E., Mística y romanticismo. Las fuentes místicas del romanticismo alemán, Madrid, Siruela, 2016.

${ }^{6}$ Schlegel, F., Werke in zwei Bänden, Berlin und Weimar, Aufbau-Verlag, 1980, p. 198.

${ }^{7}$ NS, III, p. 469. En este contexto de lo absoluto como un ideal metahistórico inalcanzable hay que enmarcar también lo que Novalis decía ya a Schlegel en una carta estimada en 


\section{Deseo de lo absoluto}

Pues bien, la filosofía kantiana constituye un hiato en el discurso filosófico de la modernidad, al menos tal y como se presenta en el pensamiento dogmático del siglo XVII constituyente de la cosmovisión barroca. Y ello se ve ya en la Crítica de la razón pura. No quisiera extenderme en la exposición del pensamiento kantiano más allá de lo estrictamente necesario para nuestro tema. Así que diré, para acotar el problema, que la intuición fundamental de Kant es que las férreas leyes de esa naturaleza mecánica son, en realidad, las férreas leyes de nuestro propio entendimiento. Es decir: que la mente humana, en su conocimiento objetivo del mundo, funciona como un filtro, dejando escapar ciertos aspectos de la realidad y organizando aquellos otros que caen dentro de sus propios límites, dando lugar a lo que va a ser "el nuevo [verändert] método del pensamiento, a saber, que solo conocemos a priori de las cosas lo que nosotros mismos ponemos en ella" 8 . La mente - lo que Kant llama el "entendimiento humano"- es un fabuloso procesador que organiza, esquematiza, categoriza la información que nos llega del mundo exterior y hace de esta una experiencia unificada e inteligible. Y esta unidad, a su vez, es posible en el principio fundamental que Kant denomina “apercepción”, esto es, la unidad trascendental (a priori) de la autoconciencia (die transzendentale Einheit des Selbstbewusstseins) ${ }^{9}$.

La cuestión era, como es bien sabido, de qué manera puedo conocer algo a priori de la realidad antes de tener una experiencia sensible de ella (no un "antes" temporal, evidentemente, pues "no hay ninguna duda de que todo conocimiento comienza con la experiencia" ${ }^{10}$, según aclara Kant al inicio de la Introducción de su primera Crítica, pero sí en cuanto que ese conocimiento permite anticipar fenómenos de acuerdo a las leyes del entendimiento). Kant se da cuenta de que la única manera de que podamos conocer a priori una regularidad (es decir, un hecho empírico sometido a leyes) es que esas leyes formen parte de la estructura misma de nuestra mente, pero entendiendo por "mente" el sujeto transcendental, no el sujeto empírico. Cualquier cosa de la que tengamos experiencia estará sometida a las condiciones generales de la experiencia humana. Cualquier cosa que

torno al 20 de agosto de 1793: "Bebiste de la fuente de los sedientos, y ahora eres insaciable", NS, IV, p. 124.

${ }^{8}$ Kant, I., Kritik der reinen Vernunft [en adelante Krv] 1, Werkausgabe Band III, Frankfurt am Main, Suhrkamp, 1956, p. 26.

${ }^{9}$ Kant, I., KrV, pp. 136-138.

${ }^{10} \mathrm{Ibid}$, p. 45. 
comprendamos estará sometida a las condiciones de la comprensión humana. Esto implica algo fundamental: que existen los límites del conocimiento. Aquello que, por su naturaleza, escapa a las condiciones finitas de nuestra mente, jamás podrá ser conocido por nosotros como objeto. Intentar conocer teóricamente a Dios o el alma o la libertad (realidades que, por su propia definición, van más allá de conceptos como tiempo, espacio y causa) sería como si una hormiga intentase conocer el teorema de Tales. No es que no existan: es que no tiene sentido aplicarles el concepto de existencia. Aquí no tiene sentido ni afirmar ni negar: no hay conocimiento posible, ni para afirmar su realidad ni para negarla. En todo caso, de la libertad tenemos (solo) una experiencia práctica. Tal es la base última de una fe racional.

La estructura de nuestra sensibilidad y de nuestro entendimiento, por tanto, nos permiten comprender el mundo y anticiparnos a fenómenos que, de otro modo, no podríamos predecir. Pero estamos literalmente atrapados en esa estructura, lo que implica una limitación en cuanto a lo que podemos conocer. Necesariamente nos ofrece un mundo filtrado. Novalis, comentando a Fichte, dirá más tarde que solo tenemos una imagen del ser ${ }^{11}$. Y toda imagen es una alteración. Por ello, en cierto sentido, se podría decir que, después de Kant, ya no podemos creer que el mundo pueda presentarse a nuestra conciencia en una imagen transparente, plena y definitiva. En primer lugar, porque esa misma conciencia sólo es posible como unificación de intuiciones recibidas, y no producidas por ella ${ }^{12}$. Esa conciencia, además, no puede ser representada más que como la unidad de lo dado a ella. En último término, esa conciencia no es una parte del mundo, como repetiría Wittgenstein muchos años después.

Este mismo horizonte de precariedad de la razón se repite en la filosofía práctica de Kant. Porque, si no podemos estar seguros de que seamos libres, sí podemos suponernos libres: esto es lo que Kant llama una "fe racional". Racional, pero fe al fin y al cabo, que no permite asegurar el triunfo del bien ni mucho menos su conjugación con la felicidad personal. Estamos solos ante el universo y ante la conciencia moral. No tengo un conocimiento objetivo de mi propia libertad: tal vez soy como la piedra de Spinoza, igno-

11 "La conciencia es la esfera del saber. En el sentimiento puede aparecer ésta sólo de forma inmediata. (...) La conciencia es un ser fuera del ser en el ser. ¿Qué es esto? El fuera-delser no puede ser un verdadero ser. Un ser inauténtico fuera del ser es una imagen, por tanto, ese fuera-del-ser debe ser una imagen del ser en el ser. La conciencia es, consecuentemente, una imagen del ser en el ser” (NS, II, pp. 105-106).

${ }^{12}$ Cf. Kant, I., KrV, p. 93. 
rante de las causas que la determinan a actuar de cierta manera. Pero Kant abre un espacio distinto: tal vez haya un núcleo de libertad en mí mismo, un alma, o como quiera llamarla, una subjetividad libre de condicionamientos, desde la que tiene sentido una verdadera autodeterminación de la voluntad. A pesar de la limitación que supone la filosofía de Kant, a pesar de delimitar lo que podemos conocer y lo que no, y precisamente gracias a ello, Kant ha conquistado un nuevo espacio de verdadera libertad para el hombre, sacándolo de la caverna del mecanicismo barroco: precisamente porque el conocimiento no tiene ahí espacio alguno, el hombre tiene derecho a una experiencia práctica de la libertad. Y tiene derecho no solamente porque no se ha demostrado que no sea libre, sino porque su propia racionalidad lo empuja a actuar como un ser libre. Para Kant, el hombre tiene una sensibilidad que le permite tener experiencia de los objetos sensibles; tiene también un entendimiento que le permite conocer el funcionamiento de esos objetos; pero además tiene una razón, que lo impulsa a traspasar siempre los límites de lo ya conocido. Por eso se podría decir que, para Kant, la razón es deseo de absoluto. O deseo absoluto. Un deseo de ir siempre más allá de las condiciones impuestas: más allá del conocimiento, sí, pero más allá también de los límites que la historia y la realidad empírica imponen a la esencia racional del hombre. La razón es emancipadora en este sentido: en cuanto permanente impugnación de lo condicionado. Y esta es la idea que se abre paso en el seno del movimiento romántico, más allá de la evidente conexión con los conceptos estrictamente estéticos.

Se dice a menudo, con buenos motivos, que la de Kant es una ética rigorista. No en vano se empeña en explicar que el deber ha de darse en el modo de un imperativo, pues se nos da siempre en oposición a nuestras inclinaciones naturales. Acojo mi deber de salvar a una anciana en un edificio en llamas contra una enorme cantidad de pasiones que me incitan a actuar precisamente en dirección contraria, entre ellas el deseo efectivo de proteger mi vida y mi salud, la indiferencia que siento hacia esa persona desconocida, el miedo al dolor, etcétera. Generalmente, pues, la moral es en Kant algo que tiene un rostro severo e inflexible, una voz que nos ordena todo aquello que se opone a cuanto nosotros consideramos camino de nuestra felicidad. Sin embargo, en ciertos textos (concretamente en algunas de sus Lecciones de ética y en ciertos párrafos de La religión dentro de los límites de la mera razón), Kant nos ofrece otra cara del deber: según explica, la sola existencia en nosotros de una ley moral que está por encima de nuestras inclinaciones naturales debiera ser para nosotros un objeto de admiración tal, que no 
podríamos sino ejecutarlo con alegría ${ }^{13}$. O dicho de otra forma: la ley moral es algo tan absolutamente extraordinario en nosotros que su discernimiento y ejecución deberían ser, por sí mismos, fuente de una alegría más perfecta. Efectivamente, el hecho de que un ser sensible, sometido a pasiones, instintos y necesidades naturales, acoja en lo más íntimo de su ser una ley moral universal e incondicionada es el único testimonio de su humanidad, de su dignidad y, en último término, de su filiación divina. Como se pregunta en La religión dentro de los límites de la mera razón, “¿qué es esto que hay en nosotros (...) por lo que nosotros, seres constantemente dependientes de la naturaleza por tantas necesidades, al mismo tiempo somos elevados -en la idea de una disposición original (en nosotros) - por encima de esas necesidades hasta tal punto que las tenemos en su totalidad por nada y a nosotros mismos por indignos de existir si hubiésemos de permanecer absortos en su goce $(. .$.$) en contra de una ley por la cual nuestra razón ordena poderosa-$ mente sin con ello prometer nada ni amenazar con nada" ${ }^{14}$. Y más adelante: "El carácter insondable de esta disposición, que anuncia su origen divino, tiene que actuar sobre el ánimo hasta el entusiasmo [Begeisterung] y fortalecerlo para los sacrificios que pueda imponerle el respeto por su deber" ${ }^{15}$.

Así pues, en su filosofía moral Kant unifica la razón y el deseo (si bien no se trata aquí de un deseo empírico, sensible): la razón desea la unidad, aunque nunca la consiga del todo. Se despliega en una unendliche Annäherung, una aproximación infinita. Y este deseo hay que entenderlo en su doble dimensión: por un lado, implica la afirmación de un objeto como bueno. Ya Aristóteles vio que es una relación inmanente la que hay entre el deseo y el bien (decir que deseamos el bien no es una mera tautología, sino la constatación del carácter afirmativo que tiene el deseo en relación con su objeto). Pero también el deseo conlleva la dimensión de la lejanía y el dolor, porque aquello que persigue la razón nunca puede ser alcanzado. Y este dolor, esta fractura entre aquello que la razón anhela y aquello que está presente en la historia, es el origen de la melancolía romántica y de una serie de conceptos que se tematizarán en el siglo posterior, especialmente a partir de la obra de Schiller. En este artículo vamos a abordar las obras teóricas de Schiller,

${ }^{13}$ Así, por ejemplo, en La religión dentro de los límites de la mera razón, en respuesta precisamente a Schiller, afirma que un sentimiento negativo frente a la ley moral esconde "un odio oculto a la ley" y que la alegría es, en cambio, "signo de la autenticidad de la intención virtuosa" (Werkausgabe, Band VIII, cit., pp. 669-670), lo que supone una importante matización a pasajes bien conocidos de la Fundamentación de la metafísica de las costumbres.

${ }^{14}$ Ibid, p. 700.

${ }^{15}$ Ibid, pp. 700-701. 
Herder y Novalis solo en la medida en que estas puedan ser interpretadas como respuestas convergentes al problema específico de la emancipación, dejando al margen amplios aspectos de su pensamiento que exigirían estudios específicos.

\section{La belleza en el camino hacia la libertad}

Schiller es un poeta que llega a la reflexión a través de los problemas que le plantea su quehacer literario, pero también desde las preocupaciones ético-políticas propias de su tiempo y que se manifiestan expresamente en sus obras de carácter histórico. Como poeta sabe que toda poesía es un intento por salir de los condicionamientos de lo empírico: un empeño por hacer sensible lo suprasensible ${ }^{16}$, por llevar al mundo de lo condicionado el ideal incondicionado de la razón, lo cual es, a su vez, el impulso fundamental de la revolución política. Al reflexionar sobre la actividad poética, Schiller se da cuenta de que la poesía tiene dos objetos fundamentales: lo que tenemos (la vida tal y como se presenta en su plena disponibilidad) y lo que no tenemos (la vida en cuanto que ha quedado atrás en el tiempo y ya no está nunca disponible). El poeta vuelve al mundo para contar lo que ama: lo que tiene frente a sí o lo que en todo tiempo se ha escapado. Y el poeta es aquél para quien todo contar es un cantar. En definitiva, para Schiller algunos poetas aman, cuentan y cantan lo que tienen. Los llamó "ingenuos". Y en verdad "ingenuo" es el hombre inmune a la nostalgia y a la esperanza. Ese hombre, como un niño que juega, parece flotar muy por encima de la amenaza del tiempo, inconsciente de que éste es Juez de todo cuanto hay y de que su sentencia siempre es la misma. O tal vez no sea inconsciencia, sino indiferencia: mientras yo exista — se dirá a sí mismo- existirá el presente para mí, y podré cantarlo. Un epicúreo desprecio de la muerte, quizá. Junto a estos, Schiller encontró ciertos poetas vueltos de espaldas al ahora, y que se arrastran afanosamente en busca del tiempo perdido. Los llamó "senti-

${ }^{16}$ Cf. Wolfgang Janke, "Die Zeit in der Zeit aufheben. Der transzendentale Weg in Schillers Philosophie der Schönheit”, en: Kant-Studien, 58, 1967, pp. 433-457. La idea la anuncia, por lo demás, el propio Kant en la Crítica del juicio: "El poeta se atreve a hacer sensibles ideas de la razón de seres invisibles (...) O también se atreve a hacer sensible aquello de que ciertamente encuentra ejemplos en la experiencia (...) más allá de las limitaciones de la experiencia, mediante una imaginación que quiere igualar el juego de la razón en la consecución de un máximo, en una perfección de la que no se encuentra ejemplo en la naturaleza. Y es propiamente en la poesía donde se puede mostrar la facultad de las ideas estéticas en toda su magnitud" (Kritik der Urteilskraft, Werkausgabe, Band X, cit., p. 250). 
mentales”. El instinto del que brota su canto es la tristeza. La tristeza entendida como un instinto de vida más allá de esta vida. Y esta poesía sentimental, esta poesía que para Schiller es específica y radicalmente moderna, es la confirmación de la intuición fundamental de la filosofía de Kant: la razón, el núcleo incandescente de la vida espiritual del hombre, es el deseo de algo que nunca está disponible, que escapa a todo intento de realización concreta. Y esto implica un concepto de historia como el escenario de esa tensión entre la razón y su propio objeto absoluto. De esta manera, lo poético tiene que ver, como señala Luciana Espinosa a propósito de la interpretación de Benjamin, con la poiesis, es decir, con la actividad propiamente productiva del espíritu ${ }^{17}$. La poesía es crítica en cuanto lleva en sí la negación de su propia finitud. Como dirá Novalis, "por medio de la renuncia voluntaria a lo absoluto, surge la infinita libre actividad: ese es el único absoluto que puede dársenos y que encontramos en nuestra incapacidad de encontrar y reconocer un absoluto. El absoluto que se nos da sólo se deja reconocer negativamente, en cuanto actuamos y encontramos que en ningún acto puede ser alcanzado aquello que buscamos" ${ }^{18}$. No hay obra de arte ideal, no hay estado perfecto, no hay acto moral absolutamente bueno. Todo es un caminar con vistas a un horizonte absoluto que nunca se alcanza.

Teniendo ante sí el problema fundamental de la estética (el arte como aquello que pretende hacer visible lo invisible), Schiller se encuentra con la obra de Kant, que le parece, según nos confiesa, deslumbrante y decepcionante al mismo tiempo ${ }^{19}$. Pues bien, se dice a menudo que Schiller encuentra en Kant el edificio conceptual adecuado para expresar sus intuiciones sobre el arte; pero antes que eso, encuentra en él un espíritu, un pensamiento que afirma la libertad y pone al hombre ante la compresión de su voluntad libre, abierta a lo incondicionado. Ese es el Kant que entusiasma a Schiller, más allá de los problemas estrictamente estéticos de la Crítica del juicio: el que dice que el fundamento del conocimiento es el "yo", que es posible una afirmación de la libertad, y que la razón está llamada a realizar sus fines en el mundo sensible.

${ }^{17}$ Cf. Espinosa, L., "Figuras de la crítica en Walter Benjamin: del romanticismo alemán a Charles Baudelaire", en: Alpha, 45, 2017, pp. 50-51.

${ }^{18}$ NS, II, pp. 269-270.

${ }^{19}$ Cf. Scholz, I., Die deutsche Klassik, Hollfeld, C. Bange Verlag, 1985, p. 13: "Su poderoso espíritu ejerció una fuerte influencia sobre los representantes del Clasicismo de Weimar; también Goethe fue estimulado por él, si bien de una forma menos duradera que a Schiller, para quien el estudio de Kant, al que se dedicaba desde 1792, trajo consigo el giro decisivo en su evolución". 
Como artista que reflexiona sobre su propia obra, Schiller tiene que enfrentarse a un problema que comparte con todos aquellos que le han precedido y sucedido en ese empeño y en esa condición. Al artista, al literato, le ha sido dada una intuición profunda y original de la realidad; en cuanto intuición es cierta, indudable, profunda, emotiva (es decir, mueve, empuja a la voluntad), pero en último término incomunicable e inexplicable. Toda intuición poética tiene algo de incomunicable: de ahí que nos parezca que cada obra de arte no se agota, y que a su vez el arte en general haya jugado siempre en los límites de lo místico. Ahora bien, ¿qué ocurre cuando se quiere llevar esta intuición fundamental artística a la reflexión y a la comunicación? Entonces es necesario que se la convierta en concepto. Pero un concepto ya no es cierto, profundo y emotivo en el sentido en que lo es una intuición poética. Por lo tanto, la verdad del arte se pierde en la verdad de la reflexión. El propio Schiller afirma tajante en la primera de sus Cartas: "Precisamente esa forma técnica, que revela esta verdad al entendimiento, se la oculta de nuevo al sentimiento" ${ }^{20}$. La forma técnica hace clara la verdad al entendimiento, pero a costa de ejercer una violencia tal sobre la naturaleza del objeto que el sentimiento ya no puede reconocer esta verdad, una verdad que le había sido mostrada (si bien deficientemente) antes a él, y que le era clara al menos como intuición. Pues bien, éste es el origen del problema en estética: la dificultad de hacer ciencia de algo — la belleza- que tiene que ver fundamentalmente con el sentimiento, sin que sea violentada o negada. Pero al mismo tiempo esboza el problema de la cultura en cuanto tal, el papel represivo y reduccionista de las formas complejas de la civilización (pensamiento, ciencia, técnica...), que afectará de lleno a la cuestión del Estado ${ }^{21}$. Schiller se enfrenta a la ambigüedad de lo técnico, un problema que será luego objeto de reflexión en autores del mundo contemporáneo tan distintos como Freud, Heidegger o Weber.

Schiller se plantea un problema más en relación a la ciencia de lo bello: es lo que podríamos llamar el reparo histórico. La problemática histórica concreta del mundo ¿no parece convertir la estética en una pérdida de energía intelectual? Al lado de las dos otras grandes preocupaciones de Kant - la teoría del conocimiento y la ética一, ¿no resulta la estética una especie de entretenimiento para aristócratas cultivados, que aleja la solución de los

${ }^{20}$ Schiller, F., Sämtliche Werke, Band V, München, Carl Hanser Verlag, 1980, p. 571.

${ }^{21}$ Respecto a lo orgánico como contrapunto a la mecanicidad del Estado, cf. Frank, M., Der kommende Gott. Vorlesungen über die neue Mythologie, Frankfurt, Suhrkamp, 1982, pp. 155 y ss. 
verdaderos problemas que el hombre tiene ante sí? Schiller tiene dos respuestas a esto: en primer lugar — dice- el espíritu no puede someterse a lo fáctico; por lo tanto, el pensamiento debe pensar el problema de la belleza y el arte aun cuando la realidad sociohistórica no le sea favorable. El pensamiento no es siervo de la teología ni del poder, ¿acaso puede convertirse ahora en una ancilla mundi, un siervo del mundo? En segundo término - y ésta es una respuesta más concreta- la cuestión estética en Schiller se vuelve necesaria justamente para resolver la problemática política y social. Es necesario tomar el camino estético, porque es por la belleza como se llega a la libertad.

Lo peculiar de Schiller es, como digo, que extiende el problema estético a cuestiones que sobrepasan el ámbito del arte, y convierte tal problema en la clave de bóveda de todo un proyecto de liberación cultural, moral y política que recoge la senda marcada por Kant. El arte no es algo puesto por el hombre como mero objeto de goce y contemplación, sino que tiene una auténtica relevancia ontológica, una significación irrenunciable en el proceso de elevación del hombre hacia el ideal de la razón. Como tendremos ocasión de comprobar, el arte abre el espacio de la libertad; y lo sublime arranca al hombre de las cadenas de lo sensible. Lo poético tendrá siempre en Schiller, a lo largo de todos sus escritos, una función emancipadora.

En el contexto de la investigación histórica, se han elaborado todo tipo de categorías para definir, a partir de lo anteriormente dicho, el "tipo" de obra que es la de Schiller. Por lo general, este tipo de definiciones no sirven para aclarar, sino sólo para nombrar algo que, por lo demás, se explica por sí mismo. En cualquier caso, y si fuera necesario concentrar en pocas palabras la significación última de la obra de Schiller, lo podríamos llamar un "idealismo estético". La obra schilleriana es idealista porque tiene como base la afirmación de la libertad y la creencia en que la subjetividad se impone sobre las cosas; y es estética, porque encuentra en la apariencia bella el lugar en que primariamente accede el hombre a la verdad de sí mismo, de que él es, en cuanto libertad racional, absoluto.

La cuestión fundamental ahora es el concepto de la belleza. ¿Qué es la belleza y por qué puede interesar al hombre que busca la emancipación? ¿No está claro que la verdad pertenece al orden del ser mientras que la belleza pertenece al orden del aparecer? ¿Cómo puede lo aparente, lo superficial, lo accidental, revelar algo sustancial? El primer texto donde Schiller aborda seriamente el problema de un concepto objetivo de belleza no es más, en realidad, que un conjunto de cartas con su amigo Körner. Me refiero a Kallias o sobre la belleza. Allí se plantea Schiller varias formas de explicar el problema de la belleza: en primer lugar, puede intentarse 
una explicación totalmente subjetiva; según ésta, la belleza no sería más que una sensación satisfactoria en un sujeto determinado. Puede ser que a, b y c llamen "bello" a un cuadro de Rafael, pero que sólo a y b digan lo mismo de un cuadro de El Bosco, porque, al fin y al cabo, "bello" no es ninguna propiedad de los cuadros, sino sensaciones subjetivas provocadas por mecanismos complejos, de tal forma que la coincidencia de juicios en distintos sujetos no puede confundirse sin más con la universalidad. Por tanto, la belleza no puede ser explicada, ni definida, ni se pueden establecer condiciones algunas bajo las cuales todo sujeto debiera emitir el juicio estético "esto es bello". En definitiva, para esta explicación, no se puede dar un concepto de belleza. La segunda manera de acercarse al problema sería partir de la idea de que sí se puede dar un concepto semejante. Se puede decir, digamos, a priori, lo que es bello. Ahora bien, este concepto objetivo de belleza puede ser, a su vez, explicado o bien objetivamente o bien subjetivamente. Explicado objetivamente, lo bello sería una propiedad del objeto. $\mathrm{Al}$ igual que poseen otras propiedades (como el color), determinados objetos poseen, en mayor o menos medida, la propiedad "belleza", reconocible para quien sepa mirarlos del modo adecuado. Explicado subjetivamente, al modo en que Kant lo hace, el concepto de belleza no sería más que una condición subjetivo-trascendental, es decir, el modo como nuestra razón elabora determinados juicios acerca de las cosas de acuerdo - y esto es lo importante- con sus propias condiciones (las de la razón). Kant se encontraba, en efecto, con la tarea de dar una explicación completa de lo bello, que estuviera además enmarcada en el ámbito de lo estrictamente estético, y no, como en concepciones anteriores, dependiente de una teoría del bien o la verdad ${ }^{22}$. Y sin embargo, la insuficiencia del planteamiento kantiano radica para Schiller —al menos más adelante- en que el gusto tiene que ver con condiciones subjetivo-trascendentales que no pertenecen a la materialidad misma de la realidad juzgada como "bella". Y de esta manera, el momento en que Schiller comienza su propio camino filosófico es allí donde pretende conseguir ese principio objetivo del gusto que Kant no ve posible.

22 García García, J., A la libertad por la belleza. La propuesta filosófica de Friedrich Schiller, UNED, Madrid, 2000, p. 223: "El núcleo de la posición kantiana radica en que la belleza de ningún modo puede pertenecer a la materialidad del objeto sino sólo a su forma; pero como dicha forma es puesta en realidad por el sujeto que juzga, la belleza pertenece entonces a las condiciones subjetivo-trascendentales de ese objeto, al modo como lo juzgamos. Suponer que el gusto estético tiene su fundamento en la materialidad del objeto sería privar de antemano al gusto de todo principio universalmente válido, cuya fuente no podría nunca ser empírica sino sólo apriórico-trascendental”. 
Pero sin ir tan lejos, en el Kallias Schiller avanza todavía de la mano de Kant, y nos ofrece un principio de belleza meramente subjetivo: la belleza es libertad en el fenómeno ${ }^{23}$. Esto simplemente desarrolla las intuiciones fundamentales de la Crítica del Juicio y Schiller es consciente de ello. Conside$\mathrm{ra}$, sin embargo, que es un primer paso necesario el deducir la belleza de la razón, para después mostrar que es una propiedad objetiva de la cosa. No hay que obviar nunca la distinción evidente entre el hecho de que se pueda dar un concepto de belleza y el que la belleza plazca por medio de ese concepto. Ese concepto existe, pero la belleza no place por medio del mismo. Yo puedo construir una teoría filosófica para mostrar qué es la belleza y por qué nos place, pero la belleza nos placería igualmente si no tuviéramos ni idea de qué es y por qué lo hace.

"Freiheit in der Erscheinung" es como Schiller llama a la belleza. "Libertad en la apariencia", se traduce a menudo, pero podría dar lugar a una confusión: la de que habría una apariencia en contraposición a una realidad oculta bajo ella. También valdría "libertad en la aparición" o en la "presencia", es decir, en el acto mismo de comparecer una cosa. Lo que significa lo siguiente: si uno encuentra en el mundo sensible (por tanto, "exterior" al sujeto) un objeto que se muestra como determinado por sí mismo de tal modo que no parece constreñido por una causa distinta de sí mismo, entonces ese objeto debe ser entendido como un "análogo" de la autodeterminación pura de la voluntad. Esto significa "libertad en la apariencia": parecer libre. Un objeto bello puede estar regido por leyes naturales, pero lo importante es que estos elementos no "comparezcan"; el objeto bello tiene que aparecer libre de reglas. Es evidente que ni en la naturaleza ni en el arte hay ningún objeto que se determine por sí mismo; de lo que se trata es de tomar los objetos tal y como aparecen, pues estamos en el ámbito de lo estético, no en el de la ciencia: "Por lo tanto, se podrá sostener como un principio lo siguiente: que un objeto se representa a sí mismo como libre en la intuición, cuando la forma del mismo no hace necesaria al entendimiento reflexivo la búsqueda de un principio. Bello, por tanto, es una forma que se explica por sí misma. Pero "explicarse por sí misma" significa aquí explicarse sin ayuda de un concepto. Un triángulo se explica por sí mismo, pero sólo por medio de un concepto. Una línea curva se explica a sí misma sin ayuda de concepto. Por lo tanto, puede decirse que bello es una forma que no exige ninguna explicación, o también, que se explica sin concepto" ${ }^{24}$.

${ }^{23}$ Cf. Schiller, F., Sämtliche Werke, cit., p. 400.

${ }^{24}$ Schiller, F., id., pp. 402-403. 
Para demostrar que ciertamente la belleza es libertad en la aparición, Schiller necesita encontrar la cualidad objetiva de los objetos que, al ser representada, nos obligara a producir la idea de libertad y referirla a ese objeto. La forma de un objeto que apunta a una regla la llama Schiller "conforme a arte", es decir, "técnica". La técnica es la condición de nuestra representación de la libertad. Sólo por medio de ella puede exponerse sensiblemente la libertad. No debemos olvidar que el planteamiento de Schiller hunde sus raíces en los logros del sistema crítico. Así, teniendo a la vista lo demostrado por Kant, Schiller se da cuenta de lo siguiente: dado que la belleza es independiente de conceptos, no se la puede hallar en la razón teórica; sin embargo, la razón práctica puede ver en la naturaleza una acción autónoma, puede ver en la naturaleza libertad: "Pero porque esta libertad le es meramente prestada al objeto por la razón, dado que nada puede ser libre sino lo suprasensible y porque la libertad misma nunca puede darse como tal en los sentidos, en resumen, dado que de lo que trata aquí es de que un objeto parezca libre, no de que lo sea realmente, esta analogía de un objeto con la forma de la razón no es entonces libertad de hecho, sino meramente libertad en la aparición, autonomía en la aparición" 25 . Se puede interpretar entonces la belleza como una experiencia de la libertad. En la belleza se manifiesta el proyecto emancipador de la razón misma. Este es el motivo por el que lo estético va a ser concebido como un vehículo de emancipación y por el que los primeros románticos van a elaborar el proyecto de una nueva mitología y de una paideia estética con vistas a una consumación histórica de la libertad.

Según lo dicho hasta ahora, existe una belleza moral. La transformación del mundo, la destrucción de las condiciones empíricas que sostienen la alienación del hombre, son acontecimientos hermosos. En un texto enviado a Körner, Schiller desarrolla una fábula para explicar qué entiende él bajo este concepto. La parábola — de claras resonancias bíblicas- nos hace imaginar a un hombre herido que pide ayuda al borde de un camino. Distintos personajes le niegan su auxilio, se lo ofrecen por razones inaceptables o le piden algo a cambio. Algún personaje actúa por egoísmo, otro por compasión, alguno incluso por respeto al deber. Pero de todos ellos, Schiller sólo resalta la acción de aquél que, viendo al herido, salta rápidamente de su caballo y corre a ayudarle. Éste es alguien para quien el deber no parece constreñir, sino que mueve a actuar como mueve el instinto: espontáneamente. Este personaje de la fábula schilleriana es alguien para quien el deber se

\footnotetext{
${ }^{25}$ Schiller, F., id., p. 400.
} 
ha convertido en naturaleza. La acción moral ha perdido la forma de una obligación y se ha convertido en instinto. De la acción de éste dice Schiller que es bella ${ }^{26}$.

La idea de una belleza moral es, en cierto sentido, una reinvención de la vieja teoría clásica de la virtud, y Schiller mismo lo confiesa así. En la virtud tal y como la entendían los clásicos, el hombre ha llegado a tal "familiaridad" con el deber, con la razón, que lo que en un principio aparece como permanente agresión a los intereses de la naturaleza, se ha convertido en la más diáfana expresión de la esencia del hombre. El bien es, en la virtud, naturaleza, espontaneidad. Cuando ha llegado a ser eso, este bien es bello.

El problema de la belleza moral lo aborda Schiller también en un escrito del mismo año: Sobre gracia y dignidad (1793). La argumentación de Schiller en este texto comienza planteando tres relaciones posibles en la naturaleza doble del hombre. En primer lugar, el hombre racional puede oprimir al sensible; por el contrario, el hombre sensible puede oprimir al racional; puede ocurrir, por último, que los impulsos sensibles concuerden con leyes racionales, y que el hombre esté en armonía consigo mismo. El esquema schilleriano se repite continuamente de este modo: dos extremos que desestabilizan la naturaleza humana integral, y una solución armónica que integra y supera positivamente los impulsos, digamos, caóticos. Pues bien, para que esa tercera opción sea posible, el acto moral debe producir una satisfacción. Sólo es posible que ley racional y natural concuerden cuando el principio moral se realiza del mismo modo que la satisfacción de un instinto: "De la misma forma que estoy convencido - y precisamente porque lo estoy - de que la participación de la inclinación en una acción libre nada demuestra en cuanto a la pura adecuación al deber de ese acto, así creo poder deducir justamente de ello que la perfección ética del hombre sólo puede mostrarse por esa participación de la inclinación en su acción moral. Porque el hombre no está determinado a realizar acciones morales, sino a ser un ser moral. Le está prescrito, no las virtudes, sino la virtud, y la virtud no es más que una inclinación al deber" ${ }^{27}$.

Hay que tener en cuenta - y esto se ve especialmente bien en las Cartas sobre la educación estética del hombre- que para Schiller no sólo la razón tiene exigencias irrenunciables en el hombre, sino también la naturaleza. De

${ }^{26}$ Con todo, en el ensayo Sobre gracia y dignidad, al que nos referiremos inmediatamente, especifica que, si bien la acción contraria a la inclinación no tiene gracia (Anmut), sí tiene en cambio dignidad (Würde).

27 Schiller, F., id., pp. 464-465. 
ahí que todo su empeño sea siempre dilucidar la posibilidad de que ambas exigencias sean satisfechas; y esto, que se sitúa en el contexto moderno de lo estético, reconstruye al mismo tiempo, como hemos dicho, toda la teoría clásica de la virtud. Es evidente, por lo demás, que el planteamiento de Schiller se encuentra en medio de una polémica con Kant, a quien por otra parte Schiller dedica epítetos del tipo "el inmortal autor de la Crítica" o "gran sabio universal". El concepto kantiano de "deber" está formulado —al menos en los grandes textos de la década de 1780 - en términos de opresión al impulso, y no de reconciliación. Schiller considera que Kant ha dado por supuesto que la inclinación hace impuro el acto moral, y que éste debe realizarse contra la inclinación o al menos con su ausencia absoluta ${ }^{28}$. Pues bien, a la persona que aúna armónicamente deber e impulso la llama Schiller "alma bella", expresión fundamental en la retórica romántica y que tendrá una importancia destacable en el conjunto de la obra teórica schilleriana. Kant ha sentado las bases de la libertad moderna y ahora es el momento de darle una forma estética, una realización artística. La emancipación moderna no es posible sin una mitología de la razón ${ }^{29}$.

\section{Mitología y emancipación}

El nexo entre emancipación y mitología podemos verlo, no solo en la manera como Schiller deja entrever el problema, sino también y explícitamente en la obra de Herder y de Novalis. Herder, en concreto, fue uno de los grandes portavoces de una visión del mito que rompía la concepción ilustrada del mismo como mera superstición. Fontenelle (El origen de las fábulas, 1724) dio cuerpo a la visión ilustrada del mito como modo representativo propia de épocas no desarrolladas. Para él, la función del mito en la literatura sería meramente retórica, como una especie de adorno estético. Gottsched (Ensayo de una poética crítica, 1730) mantiene y extiende esta visión en el mundo germánico. Pues bien: dos críticos suizos, Bodmer y Breitinger, van a comenzar una polémica contra las ideas de Gottsched, en especial a raíz de la publicación por parte de Bodmer de una traducción (1732) de la obra de Milton El paraíso perdido, muy criticada por Gotts-

\footnotetext{
${ }^{28}$ Un desarrollo interesante de esta cuestión se puede encontrar en: Max Scheler, El resentimiento en la moral, Madrid, Caparrós Editores, 1993.

${ }^{29}$ Respecto a la mitología como necesario nexo entre lo incondicionado y la realidad empírica, puede consultarse: Leyte, A., "Por una mitología de la razón”, en: Er. Revista de Filosofía, Sevilla, año VIII, $\mathrm{n}^{\circ} 15$.
} 
ched por sus excesos fantásticos. La posición de Herder se sitúa pronto al lado de Bodmer y Breitinger en su reivindicación del valor estético y moral de lo mitológico, como encontramos en su obra De la nueva utilización de la mitología (1767).

En el intento por superar el carácter escindido de la cultura moderna, Herder considera que, por decirlo así, la mitología del presente no es algo que deba ser reivindicado, ni mucho menos inventado. Se encuentra -oculta por el academicismo - en el auténtico medio en que se gesta toda cultura verdadera: el pueblo. El espíritu del mundo (Weltgeist) se manifiesta históricamente en los productos culturales de cada nación (Volksgeist). En esta línea interpreta Rüdiger Safranski el viaje en barco que emprende Herder el 17 de mayo de 1769: "Variar el elemento vital, cambiar lo firme por lo fluido, lo conocido por lo desconocido. Significaba ganar distancia y amplitud. También hay algo del pathos de un nuevo comienzo. Una vivencia de conversión, un viraje interior, totalmente del mismo modo que, veinte años atrás, Rousseau había vivido su gran inspiración bajo un árbol de camino a Vicennes: el reencuentro de la verdadera naturaleza bajo la costra de la civilización" ${ }^{30}$.

La posición de Herder anticipa, desde otro enfoque, los problemas que Schiller plantea respecto a la perfección estética de la moral y que Novalis resuelve en el camino de la nueva mitología romántica. Como hemos visto, Schiller consideraba que la escisión más propia de la cultura moderna podría resumirse en la fragmentación entre libertad y naturaleza. La cultura moderna ha producido un tipo de hombre, el "salvaje", que sólo reconoce la naturaleza, rechazando todo vínculo racional, espiritual o moral. Pero también, y especialmente, la cultura moderna es artífice de lo que Schiller llama el "bárbaro", un tipo humano que sólo valora y protege la parte racional y moral de la existencia, rechazando los sentimientos, pasiones, y todo lo que lo une con la naturaleza. La superación de esta escisión viene dada, en el pensamiento de Schiller, por la necesidad de una "educación estética" del hombre, pues es en la belleza donde se reconcilian libertad y naturaleza, razón y sensibilidad. Y este es el motivo por el que el objeto último del progreso moral tiene esa forma mitológica que Herder reivindica frente a los ilustrados y que Novalis termina asumiendo en su propio proyecto filosófico cuando afirma que "la forma acabada de la ciencia debe ser poética" ${ }^{1}$. Para Novalis, "lo poético" expresa lo absoluto mismo, es decir,

\footnotetext{
${ }^{30}$ Cf. Safranski, R., Romantik. Eine deutsche Affäre, München, Carl Hanser Verlag, 2007, p. 17.

31 NS, II, p. 527.
} 
la realidad en cuanto no condicionada y, por tanto, la poesía romántica va a ser el género apropiado para expresar un absoluto que se manifiesta negativamente en la historia. Como dice Schlegel, "la poesía romántica es una poesía progresiva universal. Su meta no es simplemente unir otra vez todos los géneros de la poesía y hacer que la poesía se de la mano con la filosofía y la retórica. Quiere, y debe también, unir o fundir poesía y prosa, genialidad y crítica, poesía del arte y poesía de la naturaleza, y hacer poéticas la vida y la sociedad" 32 . La mitología — por decirlo ahora en el lenguaje del Systemprogramm - abre paso a una representación de la unidad última de todas las cosas, la síntesis entre el monoteísmo de la razón y del corazón y el politeísmo de la imaginación y del arte. El fin de tal mitología es volver estéticas las ideas, para así allanar el camino revolucionario de una consumación emancipada de la historia.

Por lo tanto, hay un reto en el clasicismo y el romanticismo, que es a la vez político, filosófico, moral y estético: superar las escisiones propias de la cultura moderna en cuanto estas escisiones son las que imposibilitan un reencuentro emancipador del hombre consigo mismo. En Schiller, ese reto tiene como modelo el mundo griego, pero, al igual que en $\mathrm{Herder}^{33}$, ese modelo no se presenta como válido para ser trasplantado al mundo moderno. En esto Schiller es mucho menos ingenuo que el neoclasicismo artístico: Grecia es un mundo perdido ${ }^{34}$. Lo mismo piensan Herder y Novalis, pero también Fichte, que se expresa en los siguientes términos: "Concebido idealmente - en cuyo punto de vista es inalcanzable, como todo lo ideal- [el estado de naturaleza] es aquella Edad de Oro del placer sensible sin trabajo corporal que describen los antiguos poetas. Está por tanto ante nosotros lo que Rousseau y aquellos poetas ponían tras nosotros bajo el nombre de un estado de naturaleza" ${ }^{35}$. En palabras de Novalis: "La representación del pasado nos dirige hacia la muerte, hacia la evaporación. La representación del futuro, nos lleva a la revitalización, al encarnar, a la

32 Schlegel, F., Athenäums-Fragmente, en: Kritische Friedrich-Schlegel-Ausgabe, tomo II, Verlag Ferdinand Schöningh, München-Paderborn-Wien, 1967, p. 182.

${ }^{33}$ En su Filosofía de la historia describe Grecia con una adolescencia que uno abandona para siempre y de la que queda el recuerdo de la jovialidad. Herder, Filosofía de la historia para la educación de la humanidad, Sevilla, Espuela de Plata, 2007, pp. 43 y ss.

${ }^{34}$ Cf. al respecto: Bernal Rivera, B., La educación estética en Friedrich Schiller: armonizar sentir y pensar, Revista Filosofía UIS, 19, n¹, 2020, pp. 81-101.

${ }^{35}$ Fichte, Über die Bestimmung des Gelehrten, en: Werke, Band VI, Berlin, Walter de Gruyter \& Co., 1971, pp. 342-343. Respecto al tema de la Edad de Oro, en la obra de Novalis, cf.: Mähl, Die Idee des goldenen Zeitalters im Werk des Novalis, Heidelberg, Carl Winter, 1965. 
actividad asimiladora" ${ }^{36}$. Así pues, Schiller, Herder y Novalis asumen en idénticos términos que las soluciones a los problemas de la modernidad han de ser específicamente modernos. Como dice Schiller en Poesía ingenua y poesía sentimental, el mundo moderno es el de una conciencia rota, que se experimenta a sí mismo desde la pérdida de una unidad originaria. Por eso, la poesía moderna es sentimental, frente al carácter ingenuo (no separado, inmediato) de la poesía griega: señala lo que falta, no para sumirnos en una melancolía opiácea del pasado, sino para despertar el anhelo revolucionario de un futuro mejor.

La nueva mitología tiene una forma poética. No se trata meramente de un género literario más: lo poético hace referencia a un tipo de lenguaje que es previo a la escisión propia del entendimiento, que expresa la realidad unitaria del mundo. En su Tratado sobre el origen de la lengua, Herder explica que el lenguaje no es simplemente el vehículo necesario de la comunicación, sino también expresión originaria del espíritu humano. La poesía es así previa a la prosa. En esto formula una idea que desarrollará después Novalis en sus escritos sobre Fichte, y Hölderlin en su texto "Juicio y ser": el lenguaje prosaico, en el que se enuncia un hecho (algo se predica de un sujeto), es el origen de la fractura del entendimiento. El lenguaje divide una realidad que es, en el fondo, una. La poesía, en cambio, es el lenguaje que va más allá de la estructura predicativa ${ }^{37}$. Como dirá Schlegel más tarde: "Hay una poesía cuya esencia es la relación de lo real con lo ideal, y que por analogía con la terminología filosófica podría llamarse poesía trascendental. Empieza como sátira con la absoluta diferencia entre lo ideal y lo real, se trasforma en medio en elegía, y termina como idilio en la absoluta identidad de ambos"38. O en otro lugar: "La poesía romántica es una poesía progresiva universal. Su meta no es simplemente unir otra vez todos los géneros de la poesía y hacer que la poesía se dé la mano con la filosofía y la retórica. Quiere, y debe también, unir o fundir poesía y prosa, genialidad y crítica, poesía del arte y poesía de la naturaleza, y hacer poéticas la vida

${ }^{36} \mathrm{NS}$, II, pp. 468-470.

${ }^{37}$ Cabría mencionar aquí, al menos a pie de página, la importancia que tuvo en esta reivindicación de lo poético el texto conocido como El más antiguo programa de sistema del idealismo alemán, del que Ernst Behler dice que muestra el modelo estético de un contrapunto a las pretensiones absolutistas de la racionalidad barroca. Cf. Behler, E., Unendliche Perfektibilität. Europäische Romantik und Französische Revolution, Paderborn-MünchenWien-Zürich, Ferdinand Schöningh, 1989, p. 250 y ss.

${ }^{38}$ Schlegel, F., Athenäums-Fragmente, en: Werke, tomo II, cit., p. 204. Cf. Behler, Frühromantik, Walter de Gruyter, Berlin-New York, 1992, pp. 247-255. 
y la sociedad" 39 . Y en la misma línea se expresa Novalis: "La historia debe permanecer siempre inacabada. (...) La novela es en cierto modo la historia libre, la mitología de la historia. (Mitología, en el sentido que yo le doy, es la libre invención poética que simboliza pluralmente la realidad, etc.) ¿No debería ser posible una mitología de la naturaleza?"40.

Así, el modo como Schiller experimenta el advenimiento de un absoluto en la historia tiene que ver con el desarrollo de lo que él llama una "educación estética” del género humano. La historia, siguiendo el modelo trifásico de Lessing, ha conducido a una doble alienación: una exaltación desmedida de la razón o una exaltación igualmente inapropiada de la naturaleza. Ambos modos de pérdida conducen a formas igualmente inaceptables de sumisión: las leyes de la moral sustituyen las leyes de la naturaleza en el mundo producido por la modernidad, sin alcanzar un verdadero espacio de libertad. Tal espacio es logrado por la experiencia estética, única experiencia de auténtica libertad en la que las fuerzas espirituales y sensibles del hombre se encuentran más allá de toda coacción. Leemos en la vigesimoséptima de sus Cartas: "en medio del terrible reino de las fuerzas y en medio del sagrado reino de las leyes, el impulso de formación estético construye imperceptiblemente un tercer reino feliz del juego y la apariencia, en el cual el hombre se desprende de los lazos de todas las relaciones, y se libera de todo lo que se llama coacción, tanto en lo físico como en lo moral" ${ }^{41}$. El punto de partida de Herder es aquí más radical que el de Schiller, pues niega abiertamente el concepto ilustrado de "historia", según el cual el pasado es entendido meramente como una sucesión de "preámbulos" imperfectos al presente de la modernidad ilustrada. Así ironiza Herder sobre la concepción ilustrada de la historia: "las fases sombrías de este período [la Edad Media] aparecen en todos los libros; todo pensador clásico que considera la policía de nuestro siglo como el non plus ultra de la humanidad tiene oportunidad de denigrar siglos enteros acusándolos de barbarie, de miserable derecho público, superstición y necedad (...). En esto abundan todos los libros de nuestros Voltaire y Hume, Robertson e Iselin y en un cuadro hermoso hacen ver cómo la ilustración y el perfeccionamiento del mundo arranca de tiempos sombríos y llega al deísmo y despotismo de las almas, o sea a la filosofía y la paz, y a todo admirador de su época se le dilata el corazón” ${ }^{42}$. Frente a todo

\footnotetext{
39 Ibid, p. 182.

${ }^{40}$ NS, III, 668.

${ }^{41}$ Schiller, Sämtliche Werke, cit., p. 662.

${ }^{42}$ Herder, Filosofía de la historia para la educación de la humanidad, cit., p. 76.
} 
ello, Herder afirma la pluralidad y la diferencia constitutiva de la historia. La historia no es sólo el resultado (racional, ilustrado), sino sus etapas, sus momentos irrecuperables, sus deficiencias, sus ruinas. La historia es el Todo porque el Absoluto es historia. No es posible aislar sus momentos y juzgarlos desde una visión abstracta del todo. Ocurre aquí como en la teoría schleiermacheriana del arte: el fragmento de una obra de arte es en sí mismo una obra de arte. Del mismo modo, cada fragmento de la historia es, en sí mismo, una totalidad que se justifica en sí misma. En palabras de Herder: "no hay nada en todo el Reino de Dios, por mucho que se me quiera convencer, que sea exclusivamente medio. Todo es medio y fin a la vez, y con toda seguridad también estos siglos" ${ }^{43}$. La historia se va a convertir así en el discurso de Dios, en la acción efectiva de la libertad abriéndose paso en todas las formas posibles de postración.

\section{Conclusiones}

Hemos abordado la reacción clásico-romántica al problema de la emancipación en la cultura moderna, una reacción ejemplificada aquí en Schiller, Herder y Novalis, pero que igualmente encontramos, como hemos sugerido brevemente, en la obra de Fichte y Schlegel entre otros. Esta reacción se origina, por un lado, en la reflexión teológica de los movimientos heterodoxos modernos, que ven en la Reforma una nueva forma de alienación: la sustitución del Papado y la Tradición por el Texto Sagrado y la Filología, tal y como aparece de manera especialmente enfática en Novalis. Los círculos pietistas, junto con otros muchos círculos de espiritualidad heterodoxa, van a intentar rescatar el núcleo moral de la religión cristiana, entendida como religión del corazón, frente a la alienación bibliolátrica del protestantismo ortodoxo. Por otro lado, y en correspondencia con ese esfuerzo, la filosofía moral y de la religión que se desarrolla en la obra de Kant supone una comprensión de la razón - así va a ser leído en los autores estudiados aquí- como deseo de absoluto, es decir, como una actividad de constante impugnación crítica del carácter deficitario de la realidad. La razón va a ser entendida, entonces, como un deseo absoluto, esto es, como un deseo que no puede satisfacerse en forma empírica alguna, sino que se mantiene en una tensión permanente hacia la realización universal del bien. Así es como la filosofía de Kant se va a unir a la teología de la historia en una conside-

\footnotetext{
${ }^{43}$ Ibídem, p. 80.
} 
ración novedosa del problema de la emancipación: el fin de la razón como realización del Reino de Dios, esto es, como negación infinita de toda forma histórica de alienación. También hemos mostrado que la especificidad de esta idea responde a la idiosincrasia de la alienación moderna: fragmentación social, desarticulación del saber, desmitologización, mecanicidad. Para mostrar todo lo anterior, hemos hecho un recorrido a través de la obra de Schiller, Herder y Novalis, analizando algunas de las consideraciones más relevantes de estos autores respecto al tema abordado: el proyecto de una paideia estética en Schiller, la comprensión de la historia como absoluto en Herder o la romantización del mundo en Novalis, destacando su conexión con el modelo kantiano de razón práctica, y esbozando algunas de sus confluencias en torno al proyecto de una nueva mitología así como los puntos en que sus respectivas obras ofrecen rasgos singulares.

\section{Bibliografía}

Behler, E., Unendliche Perfektibilität. Europäische Romantik und Französische Revolution, Paderborn-München-Wien-Zürich, Ferdinand Schöningh, 1989.

Behler, E., Frühromantik, Berlin-New York, Walter de Gruyter, 1992.

Benz, E., Mistica y romanticismo. Las fuentes místicas del romanticismo alemán, Madrid, Siruela, 2016.

Bernal Rivera, B., La educación estética en Friedrich Schiller: armonizar sentir y pensar, Revista Filosofía UIS, 19, nº $1,2020$.

Espinosa, L., "Figuras de la crítica en Walter Benjamin: del romanticismo alemán a Charles Baudelaire", en: Alpha, 45, 2017.

Fichte, Werke, Berlin, Walter de Gruyter \& Co., 1971.

García García, J., A la libertad por la belleza. La propuesta filosófica de Friedrich Schiller, Madrid, UNED, 2000.

Frank, M., Der kommende Gott. Vorlesungen über die neue Mythologie, Frankfurt, Suhrkamp, 1982.

Herder, Filosofía de la historia para la educación de la bumanidad, Sevilla, Ediciones Espuela de Plata, 2007.

Janke, W., "Die Zeit in der Zeit aufheben. Der transzendentale Weg in Schillers Philosophie der Schönheit", en: Kant-Studien, 58, 1967, pp. 433-457.

Kant, I., Werkausgabe, Frankfurt am Main, Suhrkamp, 1977.

Leyte, A., "Por una mitología de la razón", en: Er. Revista de Filosofía, Sevilla, año VIII, nº 15. 
Mähl, H.-J., Die Idee des goldenen Zeitalters im Werk des Novalis, Heidelberg, Carl Winter, 1965.

Novalis, Schriften: die Werke Friedrich von Hardenbergs, Stuttgart-BerlinKöln-Mainz, Kohlhammer Verlag. Tomo I, Das literarische Werk, 1960; Tomo II, Das philosophische Werk I, 1965; Tomo III, Das philosophische Werk II, 1968; Tomo IV, Tagebücher, Briefwechsel, Zeitgenössische Zeugnisse, 1975.

Safranski, R., Romantik. Eine deutsche Affäre, München, Carl Hanser Verlag, 2007.

Schiller, F., Sämtliche Werke, München, Carl Hanser Verlag, 1980.

Schlegel, F., Werke in zwei Bänden, Berlin und Weimar, Aufbau-Verlag, 1980.

Schlegel, F., Kritische Friedrich-Schlegel-Ausgabe, Verlag Ferdinand Schöningh, München-Paderborn-Wien, 1967. Tomo I, Studien des klassischen Altertums, 1979; Tomo II, Charasteristiken und Kritiken I (17961801), 1967.

Scholz, I., Die deutsche Klassik, Hollfeld, C. Bange Verlag, 1985.

Spinoza, B., Correspondencia, Madrid, Alianza, 1988.

Spinoza, B., Ética demostrada según el modo geométrico, Madrid, Alianza, 1998. 